\title{
Correlation of discocyte frequency and ATP concentration in preserved blood. A morphological indicator of red blood cell viability
}

M.S.S. Leonart ${ }^{1}$,

A.J. Nascimento ${ }^{2}$,

K. Nonoyama ${ }^{3}$,

C.B. Pelissari ${ }^{4}$,

A.E.M. Stinghen ${ }^{1}$ and

O.C. de O. Barretto ${ }^{5}$

\section{Correspondence}

M.S.S. Leonart

Departamento de Patologia Médica SCS/UFPR

Rua Cel. Dulcídio, 638

80420-170 Curitiba, PR

Brasil

Fax: 55 (041) 225-6365

Presented at the XI Annual Meeting of the Federação de Sociedades de Biologia Experimental, Caxambu, MG, Brasil, August 21-24, 1996.

Publication supported by FAPESP.

Received April 10, 1996 Accepted April 16, 1997
${ }^{1}$ Departamento de Patologia Médica, Universidade Federal do Paraná, 80420-170 Curitiba, PR, Brasil

${ }^{2}$ Departamento de Bioquímica, Universidade Federal do Paraná, 81531-970 Curitiba, PR, Brasil

${ }^{3}$ Instituto Adolfo Lutz, 01246-000 São Paulo, SP, Brasil

${ }^{4}$ Centro de Hematologia e Hemoterapia do Paraná, 80060-220 Curitiba, PR, Brasil

${ }^{5}$ LIM-23, Instituto de Psiquiatria, Faculdade de Medicina, Universidade de São Paulo, 05403-010 São Paulo, SP, Brasil

\section{Abstract}

Red blood cells (RBC) are viable if kept in an adequate preservative solution, although gradual changes in morphology and metabolism may occur. There is a gradual decrease in adenosine-5' -triphosphate (ATP) concentration, $\mathrm{pH}$, glucose consumption, and enzyme activity during preservation. The normal discocyte shapes are initially replaced by echinocytes and stomatocytes and, at final stages, by spherocytes, the last step before splenic sequestration. Post-transfusional survival has been correlated with the ATP concentration. RBC preserved in ADSOL, a solution containing adenine, dextrose, sodium chloride, and mannitol, are viable for transfusion for up to 6 weeks. Erythrocytes from 10 blood units taken from healthy adult donors were preserved for 12 weeks in ADSOL at $4^{\circ} \mathrm{C}$. We now report a significant correlation $\left(\mathrm{r}^{2}=0.98\right)$ between the percentage of discocytes (89 to $7 \%$ ) and ATP (100 to $10 \%$ ) concentration in ADSOLpreserved RBC. The results suggest that the percent of discocyte shapes used as an indicator of ATP concentration may be a useful indicator for quality control of RBC viability in centers which have limited assay facilities.

ADSOL, a preservative solution containing adenine, dextrose, sodium chloride, and mannitol, is employed worldwide. Erythrocytes maintained in vitro in this medium (AS-1) are viable for transfusion up to 6-7 weeks (1). Erythrocytes maintained in vitro under different conditions generate energy via anaerobic glycolysis which is followed by organic acid accumulation, $\mathrm{pH}$ decrease, and enzyme decay (2-5). Post-transfusional survival has been correlated with adenosine-
Key words

- Red blood cells

- Adenosine-5'-triphosphate

- Blood transfusion 5'-triphosphate (ATP) concentrations and morphological changes of transfused red blood cells (RBC) (6,7). Under different conditions, it has been shown that $\mathrm{RBC}$ with a high ATP concentration keep the discocyte shape and, as ATP decreases, RBC change into echinocytes and finally into spherocytes (8).

Venous blood units were collected in an experimental quadruple blood-pack with a primary container having $63 \mathrm{ml}$ of CPDA-1 
Figure 1 - Photomicrograph of human erythrocytes preserved in ADSOL for 5 weeks at $4^{\circ} \mathrm{C}$. $d$, Discocyte; e, echinocyte; st, stomatocyte; sp, spherocyte.

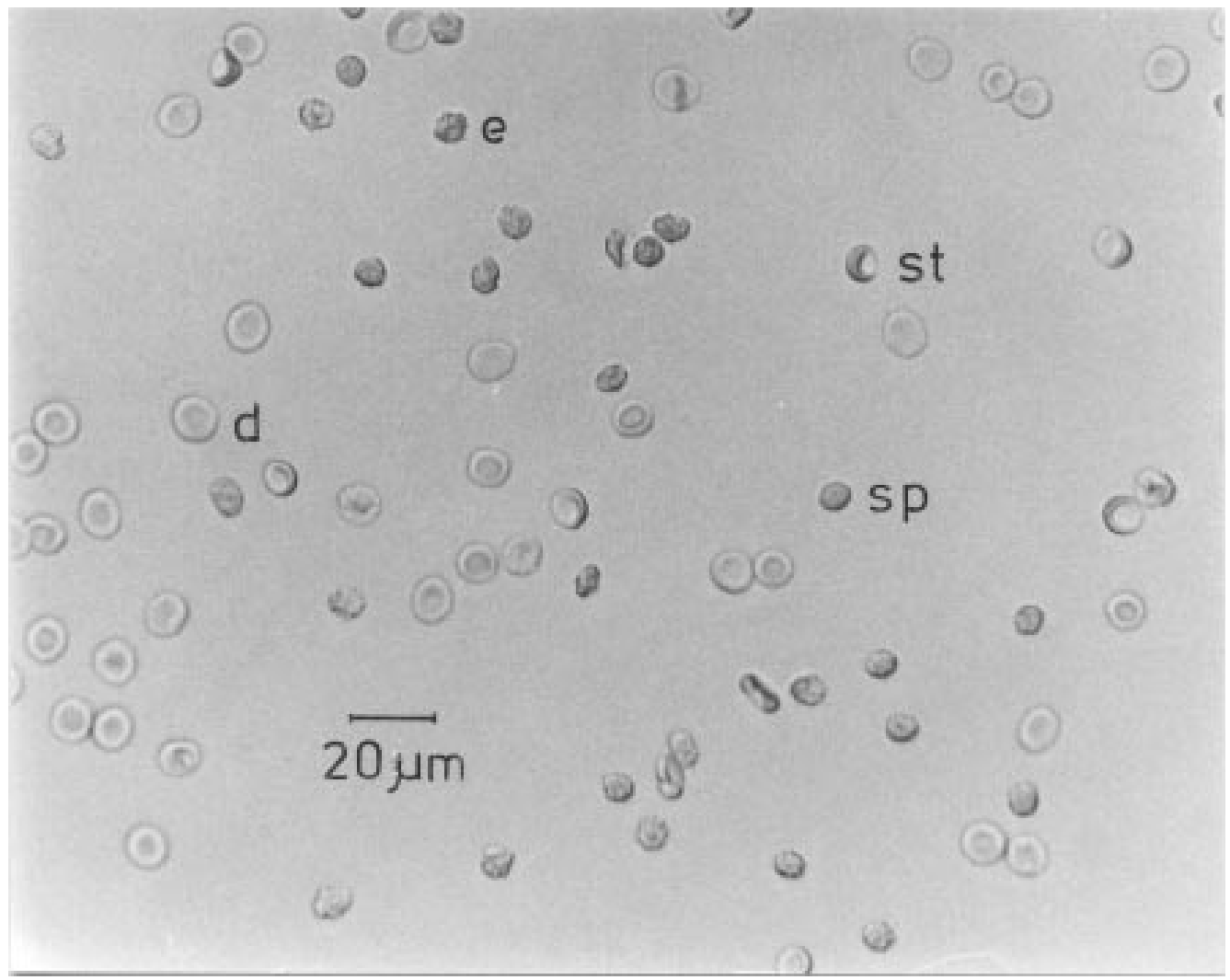

(preservative solution with citrate, phosphate, dextrose, and adenine), and 3 satellite packs, one containing $100 \mathrm{ml}$ of ADSOL and the others being empty. Blood samples (450 ml) were taken from 10 healthy adult donors and centrifuged at $600 \mathrm{~g}$ at $4^{\circ} \mathrm{C}$, and the erythrocytes from the primary container were resuspended in the same volume of ADSOL. The suspensions were transferred to sterile plastic vials and kept at $4{ }^{\circ} \mathrm{C}$. All assays were performed on the day following collection, and at intervals up to 12 weeks. Erythrocyte suspensions were diluted to 1:200 in ADSOL and classified in a Neubauer-improved hemocytometer using light microscopy within $10 \mathrm{~min}$, according to the morphological criteria of Bessis (9), simplified by Leonart (10). Discocytes, echinocytes, stomatocytes and spherocytes were counted in samples containing 1000 cells, as illustrated in Figure 1.

ATP concentrations were assayed by the method of Beutler (11) for 12 weeks. The mean of the initial values for 10 independent measurements $(4.5 \pm 0.3 \mu \mathrm{mol} \mathrm{ATP} / \mathrm{g}$ hemoglobin, equivalent to $100 \%$ ) decreased gradually and was correlated with the percentage of discocytes. Gradual changes from discocytes to spherocytes were observed over the 12 weeks of preservation. Morphological indices have been considered to be important items for quality control of RBC during storage for hemotherapy (12). Echinocytes appeared at the beginning of storage and increased up to the 6th week, when they were gradually replaced by spherocytes. The results obtained during the first 6 weeks of preservation are consistent with those observed in ADSOL (13) and SAGM (saline, adenine, glucose, and mannitol) (14). RBC preserved in ADSOL (13), SAGM (14) or in the presence of DEHP (di-(2-ethylhexyl) phthalate) (12) showed better morphological indices when compared with those stored 
in CPD (citrate, phosphate, and dextrose) or CPDA-1. Changes in ATP concentrations and hemolysis of RBC do occur during RBC preservation, and are related to the activity of membrane ATPase and therefore indicate functional integrity of the membrane (15).

Our data show that the decrease in the percentage of discocytes is positively correlated with the decrease in ATP concentration $\left(\mathrm{r}^{2}=0.98\right)$ during storage in ADSOL (Figure 2).

The analysis of the percentage of discocyte shapes providing an index for ATP concentration could be a useful tool in blood bank quality control since it may indicate RBC viability.

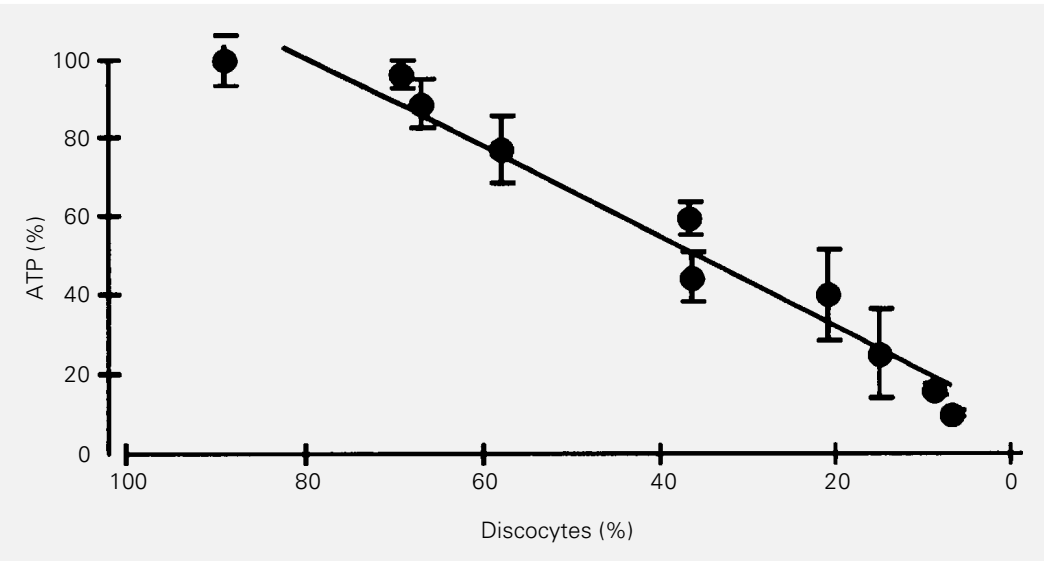

Figure 2 - Correlation between ATP concentration and percent of discocytes in blood preserved in ADSOL for 12 weeks. Data are reported as means \pm SD for 10 samples. One hundred percent ATP corresponds to $4.5 \pm 0.3 \mu \mathrm{mol}$ ATP/g hemoglobin. The circles represent the experimental data, and the full line was calculated using the best fit method.

\section{References}

1. Heaton A, Miripol J, Grapka B, Dehart D, Seeger C, Rzad L \& Aster R (1981). Improved storage of high hematocrit cell concentrates using a mannitol, adenine, saline, glucose solution. Transfusion, 21: 600-601

2. Agranenko VA (1984). Transformation of glycolysis control characteristics in human erythrocytes during blood storage. Folia Haematologica, 5: 614-621.

3. Mourad N (1969). Effect of prolonged storage on erythrocyte enzymes. Transfusion, 9: 141-142.

4. Fagiolo E, Mores N, Pelliccetti A, Gozzo ML, Zuppi C \& Littarru GP (1986). Biochemical parameters to access viability of blood storage for transfusional use. Folia Haematologica, 113: 783-789.

5. Nakao M \& Nakayama T (1980). Decrease in phosphofructokinase activity during blood preservation and the effect of intracellular ATP. Biochemical and Biophysical Research Communications, 95: 12941298.
6. Nakao M, Nakao T \& Yamazoe S (1961). Adenosine triphosphate and shape of erythrocytes. Journal of Biochemistry, 49: 487-492.

7. Dern RJ, Brewer GL \& Wiokorski JJ (1967). Studies on preservation of human blood. II. The relationship of erythrocyteadenosine triphosphate levels and other "in vitro" measures to red cell storageability. Journal of Laboratory and Clinical Medicine, 69: 968-978.

8. Watanabe S, Yamamoto R, Ogata M \& Murakami T (1985). Adenosine triphosphate restoration and discocytic transformation of stored human erythrocytes. Acta Medica Okayama, 39: 239-246.

9. Bessis M (1972). Red cell shapes: an illustrated classification and its rationale. Nouvelle Revue Française d'Hématologie, 12: 721-728

10. Leonart MSS (1994). Estudos sobre a preservação de eritrócitos. Doctoral thesis, USP, São Paulo, SP

11. Beutler E (1984). Red Cell Metabolism: A Manual of Biochemical Methods. 3rd edn. Grune \& Stratton, Orlando.
12. Estep TN, Pedersen RA, Miller TJ \& Stupar KR (1984). Characterization of erythrocyte quality during the refrigerated storage of whole blood containing di-(2ethylhexyl) phthalate. Blood, 64: 12701276

13. Greenwalt TJ, Sostok CZ \& Dumaswala UJ (1990). Studies on red blood cell preservation. Comparison of vesicle formation, morphology, and membrane lipids during storage in AS-1 and CPDA-1. Vox Sanguinis, 58: 90-93.

14. Högman CF, De Verdier $\mathrm{CH}$, Ericson A, Hedlund K \& Sandhagen B (1985). Studies on the mechanism of human red cell loss of viability during storage at $+4{ }^{\circ} \mathrm{C}$ "in vitro". Cell shape and total adenylate concentration as determining factors for posttransfusion survival. Vox Sanguinis, 48: 257-268.

15. Noble NA, Tanaka KR, Myrhe BA \& Johnson DE (1982). Red cell enzyme activities during blood storage and reactivation of phosphofructokinase. American Journal of Hematology, 13: 1-8. 